\title{
A SYNTACTICAL ANALYSIS ON SENTENCE STRUCTURE USED IN TWO ADELES'S SONGS
}

\author{
Wiyogo Purnomoadjie \\ English Teaching and Learning Program, Tarbiyah Faculty, IAIN Madura \\ Mulyadi \\ English Teaching and Learning Program, Tarbiyah Faculty, IAIN Madura \\ mulyadi_taretan@gmail.com
}

\begin{abstract}
Syntax is the branch of linguistics that described the sentence structure, songs are composed by a collection of phrases and sentences are also interested to be studied through syntax. This research aims to describe the sentence structure through a tree diagram and to find the sentence structure appears in two Adele's song, especially in writing a descriptive text. This research employs a descriptive qualitative method. Two kinds of data collection were used to collect the data, those are observation and documentation. In observation, the researcher did something such as listening to the songs "Someone Like You" and "Don't You Remember" and listening to the songs again focusing on the lyrics. In the documentation, analyzing the lyrics from each song and writing down all the lyrics of two songs to be analyzed use tree diagram. Having analyzed the data, then, finally found sixty forms of the structure of the two Adele's songs. From the two of Adele's songs used as the samples in this thesis, grammatical sentence mostly appears rather than an ungrammatical sentence. Through the discussion, the researcher also found the substandard English words, such as Ain't, you'd, I'll, you're, didn't, couldn't, isn't.
\end{abstract}

Keywords: Syntax; Sentence Structure; Adele's Songs

First Received:

September $4^{\text {th }}, 2019$
Final Proof Received:

September $9^{\text {th }}, 2019$

\section{INTRODUCTION}

A sentence is a group of words that forms an independent thought, usually including at least a subject and a verb (Spears, 2002: 535). A sentence usually has a grammatically complete statement. The network of relations between the words of a sentence is called structure. The organization of a sentence is its syntactic structure (Fabb, 2005: 2). When discussing about sentence structure, it is explained more deeply in syntax, because syntax is often equated with the study of sentence structure.

In linguistics, the study about the sentence of languages is syntax. Syntax (from Ancient Greek Syn, "together", and Taxis, "arrangement") is the study of principles and rules for constructing sentences in natural language. Syntax is the study of the principles and processes by which sentences are constructed in particular languages (Chomsky, 2002:1). English syntax discusses about the system of rules and categories that allows words to be combined to form sentences (Wafi, 2019). 
The writer uses Syntax because it enables human being to compose complete message. Traditionally, the grammar of most languages is discussed under two heads, syntax and morphology. Sentence structure in syntax can be portrayed in two ways: Phrases structure and Tree diagram. Phrases structure rules are:

a. $\mathrm{S} \rightarrow \mathrm{NP}+\mathrm{VP}$.

b. Adj $\mathrm{P} \rightarrow$ Adj.

c. $\mathrm{NP} \rightarrow \mathrm{NP}+\mathrm{S}$. Det $+\mathrm{N}$.

d. VP $\rightarrow \mathrm{V}+\mathrm{NP} . \mathrm{V}+\mathrm{VP} . \mathrm{V}+\mathrm{Adv} P$.

e. Det $\rightarrow$ Art

Tree diagram is a form of graph used to represent the syntactic structure of a phrase or sentence (Radford, 2004: 407). Sometimes a sentence has an ambiguous one and the meaning is not clear. A syntax diagram can help to understand these ambiguous sentences too.

There are many kinds of music such as rock, jazz, pop, R\&B, and rap. All those kinds of music have spread everywhere, including to our country. Western music has begotten a lot of singers who are very famous on their own music, like Britney Spears, Bryan Adams, Blue, Westlife, and Adele. Music can express our feeling and emotion. Music is a universal language, so it can touch our heart when we enjoy it and it can touch any aspects of human life. Nowadays, music has a wider connotation since it still has a rule when it is demonstrated; it is beautiful with the existence of the element of rhyme, tone, and harmony. Through its different lyric, music could arise the feeling of love, sadness, hope and happiness.

The study of sentence structure in the song becomes more important when the word or lexical items are combined into sentence found in the song. Sometimes the researcher finds the words which have different interpretation in the forms of sentence structure construction. It is why the study of sentence structure in the song becomes important.

There are many reasons why the researcher selects Adele's song as the object of this research: (1) examining the sentence structure containing in this song (2) analyzing the way of constructing the song by using tree diagram. The title of the song that analyzed by researcher are "Someone Like You", and "Don"t You Remember". Those songs were famous, and many people like those song. It caused because those songs are good to listen and the lyrics are beautiful. Those are the reason why the researcher selects Adele's song to research.

This research focuses on the analyzing the parts of sentence structures: Noun Phrase and Verb Phrase. The reason for doing this is because of the assumption that the sentence structure is the area studied by linguists in the song. In this research tree diagrams is used to analyze the data. 
Theoritically, this research will enhance the study of syntax, especially concerning with sentence structure. Practically, this research will be useful for English department student who are interested in studying syntax. So, they can use this research as references for their analysis.

\section{LITERATURE REVIEW}

\section{A Brief Description of Syntactical Theory}

a. The Understanding of Syntax

Syntax is the component of a grammar which determines how words are combined together to form phrases and sentences (Radford, 2004: 405). It can be concluded that syntax is the arrangement and relationship among words, phrases, and clauses forming sentences or larger constructions based on grammatical rules.

b. The Analysis of Syntactical Theory

Syntactic theory, as the term is used here, has its origins in Noam Chomsky's 1957 book Syntactic Structures. It can be said to have two goals. On the one hand, it is concerned to develop precise descriptions of aspects of the syntax of various languages, the ways in which specific languages combine words to form sentences. On the other hand, it aims to develop a general theory of syntax, specifying what languages have in common in this area and how they can vary. This is often known as a theory of universal grammar (Borsley, 2003: 1).

c. Traditional analysis (word class rules)

This course of a long tradition of grammatical analysis with stretches book two thousand years to the grammarian of Ancient Greece and Rome. They were describing the structures of Greek and Latin, where they discovered all the basic ideas of grammar word classes, dependency links, coordination, dependent type (such as subject and object) and form based contrast like finitness. This is so called traditional grammar which we will find alive and well in most modern book that deal with grammar, especially dictionary and grammars of foreign languages. It is also the foundation of which all modern thinking about grammar rest.

d. The Structure Theory of Linear Arrangement Analysis (Neo-Grammar)

The structural theory of language was the first major new approach to descriptive linguistics in the end twentieth century. This school was introduced by the famous Swiss linguist Ferdinand de Saussure by Leonard Bloomfield in America. This school flourished for about thirty years, until the early 1960s.

e. Transformational generative grammar

The term Transformational Generative Grammar is used to Noam Chomsky"s theories about Syntax. These theories were first rut forward in a book entitled Syntactic 
Structure which published in 1957. Chomsky tried to find certain rules which would create well-formed sentence of language. According to Chomsky, his grammar is Generative, since it can generate or is called Transformational since a basic or simple sentence like: I write a letter, it can be changed or transformed into a number of sentences with either the same meaning into A letter is written by me or with different meanings. Such as:

Do I write a letter?

I write a letter, don't I?

I don't write a letter

In the framework of transformational generative grammar, the structure of sentence is represented by phrase structure tree, otherwise known as phrase marker of tree diagram. Such tree-diagram provides information about the sentences that they represent by showing the hierarchical relations between their component parts. For example: "I took a chance".

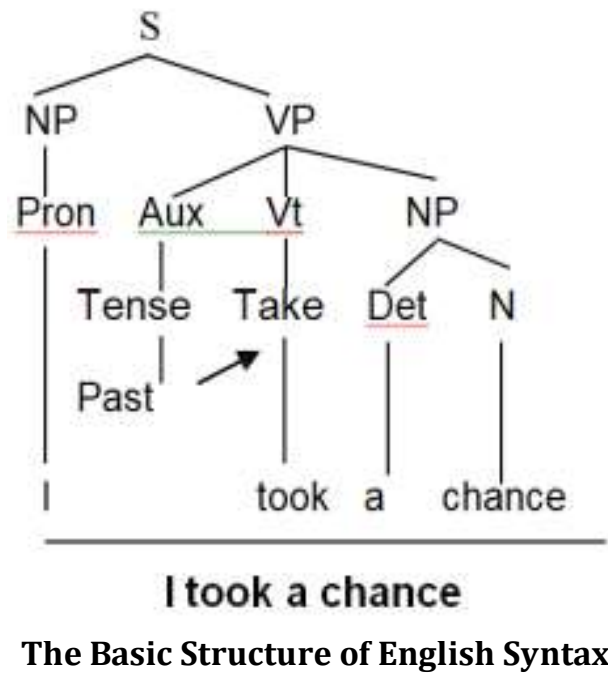

\section{a. Word class}

Every word belongs to a word class, such as noun, verb, adjective, article, conjunction, etc. Other names for word class are "category" or "part of speech" (Fabb, 2005: 11). There are eight word classes in English, they are:

1) Noun

A noun is a word used to name a person, animal, place or thing. Noun in English can be classified into two types, they are:

a) Concrete nouns

Concrete nouns refer to things which we can sense. It can be classified into:

1. Common noun is used to name all member of a class or group. Such as: teacher, table, apple, tree, bus, etc.

2. Proper noun is used to name a specific person, place or thing. Such as: John, Bali, Madura, Toba Lake, New York, etc. 
3. Material noon are used to name all materials. Such as: gold, iron, bronze, steel, silver, etc.

4. Collective noun is used to name of group. Such as: family, team, nation, people, army, etc.

b) Abstract noun

Abstract noun refer to ideas or qualities. Such as: sad, happy, tired, hungry, handsome, etc.

c) Pronoun

A pronoun is a word that replaces or stand for a noun. Examples: he, she, it. It can be divided into six types. They are:

1. Personal pronouns these show whether a person is represented is speaking, being spoken to, or spoken of; I, me, you, he, him, she, her, it, we, us, they, them.

2. Possessive pronouns these show possessive; mine, yours, him, hers, its, ours, theirs.

3. Reflexive pronouns these show identify "self"; myself, yourself, himself, herself, ourselves, itself, themself.

4. Relative pronouns these relate to antecedent, or a preceding noun or phrase; who, whose, whom, that, which, what.

5. Interrogative pronouns these are used to in asking question; who, which, what.

6. Indefinite pronouns these form refer to no one person or thing in particular; each, every, either, neither, my, all, few, some, several, one, other, another, none, both, such.

2) Verb

A verb is used to show an action or a state of being. According to the object they are requiring, verbs can be classified:

a) Transitive verbs, verbs which have direct objects (no prepositions are needed to connect verb and object); He sees the house, we believe in you.

b) Intransitive verbs, verbs which do not have a direct object. There are three types of verbs, namely: Regular verbs end in - ed or $-\mathrm{d}$.

c) Irregular verbs change forms, such as write- wrote.

d) Linking verbs express a state of being, such as shows and appear.

3) Adjective

An adjective is a word that describes or modifies a noun. An adjective can be classified into four types:

a) Possessive adjective is similar to a possessive pronoun, but it modifies a noun or a noun phrase.

b) Demonstrative adjective is identical to a demonstrative pronoun, but it is used as adjectives to modify nouns or noun phrase.

c) Interrogative adjective is like an interrogative pronoun, but it modifies a noun or noun phrase rather than standing on its own.

d) Indefinite adjective is similar to an indefinite pronoun. It modifies a noun, pronoun, and noun phrase. 
4) Adverb

An adverb is a word that describes or modifies a verb. Ex: carefully, quickly, wisely. Usually, an adverb tells you when, where, how, in what manner, or to what extent an action is performed. Many adverbs end in -ly, particularly those that are used to express how an action is performed. However, not every word ending in "ly" is an adverb: "friendly," for example, is an adjective.

5) Preposition

A preposition is a word that indicates the relationship of a noun (or noun phrase) to another word. Examples of prepositions are to, at, with, for, against, across. Nouns and pronouns most often follow prepositions. Examples of prepositions include: about, above, across, up, with, within, without.

6) Conjunction

Conjunctions are words that connect two words, phrases or sentences. Coordinating conjunctions connect two independent clauses (sentences that can stand alone) together, while subordinating conjunctions combine a subordinate to a principal element in the sentence. Examples of coordinating conjunctions include: and, or, nor but, for. Examples of subordinating conjunctions include: after, although, as, as if, as much as, as though, because, before, how, if, in order that, provided, since, than, that, though, unless, until, when, where, while.

7) Interjection

An interjection is a word that expresses emotion and has no grammatical relation to other words in the sentence. For instance: Oh!, Alas!, Nonsense!, etc.

\section{b. Phrase Structure}

A phrase structure is an expression (can be a single word, but usually more) which contains a single thought but is not necessarily a complete sentence. Phrases may be classified by the type of the head they take:

1) Noun Phrase (NP)

Noun phrase is a phrase that plays the role of a noun. The head word in a noun phrase will be a noun or a pronoun. Noun Phrase can be in the form of the following:

a) $\mathrm{NP} \rightarrow \mathrm{N}$ (dog, house)

b) NP $\rightarrow$ Pron (you, I, he)

c) NP $\rightarrow$ Pron N (John, Surabaya)

d) $\mathrm{NP} \rightarrow$ Det $+\mathrm{N}$ (a pen, the train)

e) $\mathrm{NP} \rightarrow \mathrm{NP}+\mathrm{S}$ (the girl who is driving a car)

2) Adjective phrase (AP)

Adjective phrase with an adjective as its head. For instance: full of toys, with green dress. 
3) Adverbial phrase (AdvP)

Adverbial phrase with an adverb as its head. For instance: very carefully

3) Verb phrase (VP)

Verb phrase with a verb as its head. For instance: eat cheese, jump up and down etc.

4) Prepositional phrase (PP)

Prepositional phrase with a preposition as its head. For instance: in love

\section{c. Clause Structure}

A clause consists of a subject and a verb. There are two types of clauses:

1) Independent clause

An independent clause consists of a subject verb and also demonstrates a complete thought: for example, "I am sad".

2) Dependent clause

A dependent clause consists of a subject and a verb, but demonstrates an incomplete thought. There are three main types of dependent clause:

a) Noun clause

A noun clause typically acts as the subject of a verb or as the object of a verb or preposition. For examples:

Keep thinking about what happened yesterday.

I imagine that they are having a good time.

What you say is not as important as how you say it.

b) Adjectival clause

An adjectival clause modifies a noun phrase. In English, adjectival clauses typically come at the end of their noun clause.

c) Adverbial clause

An adverbial clause typically modifies its entire main clause; at the beginning of a sentence, in the middle of a sentence, and at the end of a sentence. For examples:

Wherever Jane goes, she leaves broken heart behind.

Tom liked the meal more than Tim did because he is a greedy.

Jack wanted to quit because he was bored with his old job.

\section{d. Sentence Structure}

Sentences are made up of two parts - subjects and predicates. In sentences there are differences between the deep and surface structure. The surface structure of a sentence is its grammatical form, while the deep structure is understood as its meaning.

\section{e. Sentence Elements}

1) Sentence Elements

A normal sentence in English usually contains at least three elements: subject, verb, and object. The subject is usually a noun, a word that names a person, place, or thing. The 
something or someone that the sentence is about is called the subject of the sentence. Predicate is syntactical name marking, identifying the verb used to express the action or the state of the subject.

2) Object and Complement

An object receives the action and usually follows the verb. Object can be divided into:

a) Direct object

A direct object is a noun or pronoun that receives the action. For examples:

John" jumper no longer fits him.

She can invite whomever she wants.

b) Indirect object

Indirect object tells to or for whom something is done. For examples:

Bill gave us a pair of socks.

Jane gives a letter to me.

The term complement is used with different meanings. Complement can be classified into two; they are:

a) Subject complement

Subject complement tells more about the subject by means of the verb. The pattern is Subject + Verb + complement. For instance:

Mr. Jenner is a management consultant.

She looks well.

b) Object complement

Object complement tells more about the object by means of the verb. The pattern is Subject + Verb + Object + Complement. For instance:

We elected him chairman.

He paints the house white.

\section{Tree Diagram}

Tree diagram is a form of graph used to represent the syntactic structure of a phrase or sentence (Radford, 2009: 483). The sentence is considered the basic of the syntactic system. Instead of beginning with actual sentences, however we begin with the directions for generating or producing structural descriptions of sentences, which are set forth in phrase structure rules. The rules should be interpreted as an instruction to rewrite or expand the symbol on the left of the arrows as the sequence on the right. In S $\rightarrow \mathrm{NP}+$ VP, "S" stands for sentence, "NP" (Noun Phrase) and "VP" (Verb Phrase). The item on the left dominates the elements on the right.

\section{Songs}

A song composer interprets a poem, translates its mood atmosphere and imagery into music, also create vocal melody that is musically satisfying and perfectly moulded to 
the text. Important words are emphasized by stressed tones as melodic climax. It may be written for one or several voices and is generally performed with instrumental accompaniment. Song lyrics are not poetry, however, and it seems that the authors" problems with Sting have precisely something to do with the fact that they are not (Eckstein, 2010: 9).

From the definitions above, the writer concludes that song is a short poem, which is suitable for singing and it is used to express personal and sentimental feeling or emotion

\section{METHOD}

In this point, the researcher uses Qualitative research. Qualitative research is an inquiry approach useful for exploring and understanding a central phenomenon (Creswell, 2012: 626). Based on the definition this research just focus to the central phenomenon that happened in the field, because this research does research about syntactical analysis on sentence structure in two Adele's songs. It is based on the problem statement. Here the writer gives the description of the adjective clauses in written language using the tree diagram.

The researcher applied descriptive qualitative method to make description accurately and systematically. In collecting the data for this research, the writer followed these steps, first listening to the songs: Someone Like You and Don't You Remember, listening to the songs again focusing on the lyrics of the song, analyzing the sentence structure portrayed in tree diagram, and drawing the formula of each analyzed sentence.

To collect the data, the researcher used non participant observation, he observed only two songs. They are someone like you and don't you remember. Besides, those songs are good, they also got many awards like the Brit Awards "Critics' Choice" award and won the BBC Sound of 2008. The documents including the lyrics from those two songs and writing down all the lyrics of the song to be analyzed.

Data analysis involves reviewing the data while they are being collected and attempting to synthesize and make sense out of what is observed (Ary, Jacobs, Razavieh, \& Ary, 2010: 530). It becomes important to get the data and answer research problem stated in the previous. The data will be analyzed by using three steps of data analysis, they were data reduction, data display and conclusion drawing (Miles \& Huberman, 1994).

\section{RESULTS AND DISCUSSION}

In this part, the writer will explain about the research result of the syntactical analysis on sentence structure in two Adele's song. The writer will analyze how are sentence structure portrayed in tree diagram and what are the sentence structure found. The writer describes the research discovery which is gotten in research field either of observation result and documentation. 


\section{Someone Like You}

I heard

That you're settled down

That you found a girl and you're married now I heard

That your dreams came true

Guess she gave you things

I didn't give to you

Old friend why are you so shy

Ain't like you to hold back

Or hide from the light

Pre chorus :

I hate to turn up out of the blue uninvited

But I couldn't stay away I couldn't fight it

I had hoped you'd see my face and that you'd be reminded

That for me it isn't over

Chorus:

Never mind I'll find someone like you

I wish nothing but the best for you too

Don't forget me I beg

I'll remember you said

Sometimes it lasts in love but sometimes it hurts instead,

Sometimes it lasts in love, but sometimes it hurts instead
Yeah
You know how the time flies only yesterday
It was the time of our lives
We were born and raised in a summer haze
Bound by the surprise of our glory days

(Pre chorus) (Chorus)

Nothing compares no worries or cares

Regrets and mistakes they are memories made

Who would have known

How bittersweet this would taste

(Chorus twice)

\section{Don't You Remember}

When will I see you again

You left with no goodbye

Not a single word was said

No final kiss to seal any seams

I had no idea of the state we were in

Pre chorus:

I know I have a fickle heart and bitterness, and a wandering eye and a heaviness in my head

Chorus:

But don't you remember

Don't you remember 
The reason you loved me before

Baby please remember me once more

When was the last time you thought of me?

Or have you completely Erased me from your memory?

I often think about where I went wrong

The more I do the less I know

Pre chorus:

I know I have a fickle heart and bitterness, and a wandering eye and a heaviness in my head

(Chorus)

Gave you the space so you could breathe

I kept my distance so you would be free

And hope that you find the missing piece

To bring you back to me

(Chorus)

When will I see you again.

After collecting the lyrics of those songs. The writer attempts to analyze the data of the songs to describe the sentence structure. It is found that it appears nonstandard English words, such as Ain't, you'd, I'll, you're, didn't, couldn't, isn't.

Non-standard English, also written as nonstandard English, refers to use of English, especially regarding grammar, but also including other aspects of language, that is considered by convention to be sub-standard or not "proper". Non-Standard English is what most of us use and is all about the place we grew up in. It's about cultural identity, history and pride. Nonstandard English word can found in grammar and usage.

The word ain't is so commonly misspelled it even appears in dictionaries now. But most good dictionaries will refer to it as nonstandard. What does that mean? Simply that it's acceptable for use in informal writing or even dialogue, but not for formal professional writing. While some contractions such as "isn't" is recognized and acceptable in speech and informal written registers, others are acceptable in speech but frowned on in all written forms of the language. You will also find jargon and colloquialisms in the dictionary, but you would not use the word "ain't" in your personal essay just because it is in the dictionary. (Naturally, you could use it in dialogue).

Nonstandard English is especially appear in music like pop, rock, jazz and rap music, as well as in films, all of which tend to have international audiences, and many foreign speakers who have learnt more formal registers are sometimes surprised when they hear expressions like: "I gotta go!" (I have to go now). In certain regions, certain dialects may have this non-standard language incorporated into "normal" speech. Nonstandard forms also found in dialogue and they are used as a powerful tool to reveal character traits or social and regional differences.

There are sixty forms of the structure of lyrics of the two songs are as follows: 
S (Sentences) consists of:
1) $\mathrm{NP}+\mathrm{VP}$.
2) $\operatorname{Adv} P+N P+V P$.
3) That + NP + VP.
4) Conj + VP.
5) Conj + NP + VP.
6) $\mathrm{NP}+$ Conj + NP + VP.
7) Conj + Adv P + NP + VP.
8) Conj + That + NP + VP.

NP (Noun Phrase) consists of:

9) $\mathrm{N}+\mathrm{S}$.

10) Det $+N$.

11) Pron + N.

12) $\mathrm{Adj}+\mathrm{N}$.

13) Adj + Pron.

14) Det + Adj.

15) Det + Adj + N.

16) $\mathrm{N}+$ Conj $+\mathrm{N}$.

17) $\mathrm{N}+$ Adj + N + Conj + N

18) Pron + Det $+N$.

19) Det + Adj + N + Conj + N

20. Det + Adj + Pron .

20) Det + Adj + N + Pron .

22) Conj + Det + N.

VP (Verb Phrase) consists of:

23) Aux + Vt.

24) Aux + Vi + NP.

25) Aux + Vt + NP.

26) $A u x+V t+A d v P$.

27) $A u x+V t+S$.

28) $\mathrm{Aux}+\mathrm{Vi}+\mathrm{S}$.

29) $\mathrm{Aux}+\mathrm{Vi}+\mathrm{PP}$.

30) Adv P + Adj P.

31) $A u x+V i+A d v P$.

32) $A u x+V t+V i+P P$.

33) $\mathrm{Aux}+\mathrm{Be}+\mathrm{Vi}$.

34) $A u x+V t+V i+S$.

35) $\mathrm{PP}+\mathrm{Adv} P$. 
36) $\mathrm{Aux}+\mathrm{Vt}+\mathrm{PP}$.

37) Aux + S.

38) $\mathrm{Aux}+\mathrm{Vt}+$ Conj $+\mathrm{Vt}+\mathrm{PP}$.

39) Aux + Adv P.

40) Adv P + PP.

41) Adv P + S.

42) Aux + Be + Adj P.

43) Adv P + Aux + Vt + PP.

44) $\mathrm{PP}+\mathrm{Aux}+\mathrm{NP}$.

45) Aux + Vt + Not + VP.

46) $\mathrm{Aux}+\mathrm{Vt}+\mathrm{Not}+\mathrm{S}$.

47) Aux + Not + Adv P.

48) Aux + Not + Vt + Adv P.

49) Aux + Not + Vt + NP.

50) $\mathrm{Aux}+\mathrm{Vt}+\mathrm{Not}+\mathrm{Vi}+\mathrm{S}$.

Aux (Auxiliary) consists of:

51) Tense (Past) + Be.

52) Tense (Past) + Do.

53) Tense (Past) $+\mathrm{M}$.

54) Tense (Past) + Have.

55) Tense (Past) + M + Have.

56) Tense (Present) + Be.

57) Tense (Present) + Do.

58) Tense (Present) $+\mathrm{M}$.

PP (Prepositional Phrase) consists of:

59) Prep + NP.

Adv P (Adverbial Phrase) consists of:

60) NP + Adv.

\section{CONCLUSION}

Having discussed the data, the next step is to draw conclusions of the syntactical study concerning the sentence structure of Adele's song lyrics related to the theory of syntax based on the theory of transformational grammar using the tree diagram. It can be concluded that from the two of Adele's songs used as the samples in this thesis, grammatical sentence mostly appears rather than ungrammatical sentence. Through the discussion, the writer found the nonstandard English words, such as, Ain't, you'd, I'll, you're, didn't, couldn't, isn't. The writer also found sixty forms of the structure of lyrics of the two Adele's songs. 


\section{REFERENCES}

Ary, D., Jacobs, L. C., Razavieh, A., \& Ary, D. (2010). Introduction to research in education (8th ed). Belmont, CA: Wadsworth.

Borsley, R. D. (2003). Syntactic Theory A Unified Approach (2nd ed.). London: Arnold.

Chomsky, N. (2002). Syntactic Structures. Berlin: Mouton de Gruyter.

Creswell, J. W. (2012). Education Research. Boston: Pearson Education.

Eckstein, L. (2010). Reading Song Lyrics. New York: Rodopi.

Fabb, N. (2005). Sentence Structure. Glasgow: The University of Strathclyde.

Miles, M. B., \& Huberman, A. M. (1994). Qualitative Data Analysis (2nd ed.). London: SAGE Publications.

Radford, A. (2004). An Introduction to English Sentence Structure. New York: Cambridge University Press.

Radford, A. (2009). Analysing English Sentences A Minimalist. New York: Cambridge University Press.

Spears, R. A. (2002). NTC's Pocket Dictionary of Words and Phrases. New York: McGraw-Hill Companies.

Wafi, A. (2019). Using Games to Improve Students' Active Involvement in the Learning of English Syntax at IAIN Madura: An Autonomous Learning. OKARA: Jurnal Bahasa Dan Sastra, 13(1), 107. https://doi.org/10.19105/ojbs.v13i1.2256 